\title{
Teaching Reform and Exploration of Hospital Information Equipment Assembly and System Maintenance
}

\author{
Xin Jiang ${ }^{1, a, *}$ ZeGuo Shao ${ }^{1, b^{*}}$ \\ ${ }^{1}$ Shanghai University of Medicine \& Health Sciences, Shanghai 201318, China \\ ${ }^{2}$ Shanghai University of Medicine \& Health Sciences, Shanghai 201318, China \\ a martinjiang2004@163.com, b shaozg@sumhs.edu.cn
}

Keywords: assembly and maintenance, teaching reform, problem-based learning method (PBL).

\begin{abstract}
Hospital information equipment assembly and system maintenance" is a highly practical course, focusing on the cultivation of students ' practical ability. At present, there are still some drawbacks in this course, such as outdated textbook content, inflexible teaching methods and relatively weak practical aspect. This article carries out a new reform and exploration of teaching contents and teaching methods. In order to improve the teaching effect, this article introduces a variety of methods such as module discussion mode, problem-based learning method, microlecture mode and virtual experiment mode. The practice has proved that good teaching has been achieved which has great practical significance for improving students' practical ability.
\end{abstract}

\section{Introduction}

Hospital information system has become a powerful tool for hospital scientific management and improvement of medical service level. How to ensure the good operation of information system, timely and accurate solution of various problems in operation has become an indispensable part of the normal operation of the hospital. At the same time, hospitals and other medical institutions urgently need a large number of engineering and technical personnel to engage in such work, in order to meet its increasingly heavy day-to-day maintenance and management work. In order to meet the needs of hospitals and other medical institutions, it is necessary for universities and related institutions to train a large number of skilled professionals who are proficient in computer hardware and software technologies and network communication technologies and other skills. Accordingly our school combined with the needs of the community and the characteristics of computer science opened the "hospital information equipment assembly and system maintenance" course.

The course of "Hospital Information Equipment Assembly and System Maintenance" provides a comprehensive introduction to computer hardware theory, computer assembly technology and operating system installation and maintenance so that students can master the composition , working principle , basic functions and performance characteristics of computer hardware. At the same time students can master the common hardware and software troubleshooting methods expertly and carry out routine maintenance to meet the growing daily maintenance and management of hospital information system. Therefore this course is a combination of theory and practice focusing on practical ability training.

Faced with the needs of hospital calling for more computer hardware and software maintenance personnel, many colleges and universities in China have opened the relevant courses. Students in the fierce social competition have better conditions and ability to compete in order to have a strong competitive ability in the face of severe employment situation. Therefore, how to improve the teaching effect of "hospital information equipment assembly and system maintenance" is a problem that every teacher needs to study and discuss. 


\section{Status of the Course}

\subsection{The content of textbooks is obsolete and out of touch with reality}

Moore's law in the computer industry shows that computer hardware is upgraded every 18 months. The long-term development of textbook writing has led to a certain lag in the content of textbooks compared with the current popular technologies and even some content has been eliminated. [1] Using this kind of textbooks, not only we cannot make the student understand the current computer development situation roundly, but also we cannot achieve good teaching results, we more easily frustrate the students' enthusiasm for learning and even mislead students.

\subsection{Teaching content involves a wide range of topics}

The teaching content involves Computer Culture Foundation, Principles of Computer Organization, Electronic Technology, Principles of Operating System and other courses. The teaching content involves a wide range of topics and scalability of content is strong. There are so many knowledge points in the course and these knowledge points are dispersed. [3] Although these knowledge points are dispersed, some knowledge points have strong correlation. At the same time, computer hardware has a lot of performance indexes and each performance index has one or more professional terminology. It is difficult for students to remember so many professional terminologies. Furthermore the theoretical content of performance indexes is more abstract. The students cannot understand these theories roundly and the effect of learning is so poor.

\subsection{The teaching method is not flexible and the teaching effect is poor}

The course is mainly taken by the traditional cramming method and the process is more boring. Students may be bored because of too much theoretical explanation. Without fully mobilizing students' enthusiasm, teaching activities cannot be effectively carried out because students lose their interest in learning.

\subsection{Teaching practice is relatively weak and the experiment teaching effect is poor}

"Hospital information equipment assembly and system maintenance" is a highly practical course focusing on the close combination of theory and practice and the cultivation of practical ability of students especially. So the experimental aspects are essential. Currently our school is not equipped with specialized laboratories, the equipment used are relatively few, and the hardware is too old. Such hardware conditions have been out of the actual requirements, cannot to enable students to get the latest, effective knowledge and skills. And failure rate of these machines is higher. Students encountered a lot of random faults in the experimental process, these failures not only could not be solved in time and increased the workload of teachers, but also could not make students get targeted training. Even some students didn't want to take the old machine operation, students could not have the ability to get effective exercise.

Therefore, in order to improve the teaching effect and arouse the students' interest, it is necessary to carry on the new reform and exploration of the course content and teaching methods.

\section{Reform of the Course}

\subsection{Reforms of teaching content}

(1) Aiming at the drawback that the content of textbooks is obsolete and out of touch with reality, it is necessary to choose the textbooks which are latest published, the most cutting-edge, and the most practical and close to the real life. In addition, teachers must actively search information on the Internet and consult the latest literature and so on. In this way teachers write their own new textbooks to make up for the flaws of the textbooks in use and ensure that the content of textbook is intellectual, original and practical. Due to the lack of contact between students and the market, teachers should add a large number of pictures, animations, videos as much as possible to enhance intuitive. 
(2) Aiming at the problems of teaching contents involving a wide range of topics, some necessary knowledge points are selectively explained according to the computer development trend and the characteristics of the course. Teachers should teach the newest, elusive and practical knowledge. For example, there is no need to explain the physical structure and logical structure of hard disk when teachers explain the topic of partition and format of hard disk. Teachers should focus on the hard disk partitioning process by using popular partitioning software. At the same time, teachers should focus on the computer memory performance parameters, the hard disk technology indexes, the CPU performance parameters, the technologies of computer hardware connection, the introduction and use of common interface, the display settings and so on.

\subsection{Reforms of teaching methods}

(1) In view of the fact that the course knowledge points are too many and dispersed, and some of the knowledge points are strongly related, the related knowledge points should be extracted from the original chapters and organized into modules. According to the teaching focus, these modules are formed the special topics. For example, topic 1: basic knowledge of computer hardware; Topic 2: disassembly and assembly of computer; topic 3: basic operation of BIOS setup; topic 4: partition and format of hard disk; topic 5: installation and backup of operating system; topic 6: daily use and maintenance of computer; topic 7: management and optimization of memory, topic 8: common failures and solutions of hardware; topic 9: purchase and testing of hardware; topic 10: settings and applications of computer network. By using thematic teaching methods, the knowledge of hardware and software, the operation skills and the corresponding theories are combined to arouse the students ' intellectual curiosity, so that the students can better integrate the relevant knowledge points and the key contents are conducive to highlighted.

(2) According to the present situation that the teaching method is not flexible and the teaching effect is bad, the following methods can be used to improve the teaching effect.

(a) In order to reform the traditional cramming method, heuristic and interactive teaching methods are often used in the usual classroom teaching to encourage students to think independently and stimulate their initiative in learning. Teachers should increase the intensity of multi-media teaching and insert more animations, pictures, videos and other media elements in the courseware in order to deepen students' memory and make teaching intuitionistic. For example, teachers can use on-site operation of the demo or play videos when teachers teach the topics of hard disk partitions, data recovery, BIOS parameters, computer disassembly and assembly, etc. Teachers comment briefly during the key areas so that students have a more intuitive impression. Teachers hereby stimulate students' interest in learning, deepen the depth of understanding of students and receive a multiplier effect of teaching.

(b) With the help of campus network, teachers can build the course's Learning website or forum. Using microlecture method, teachers make PPT, flash animations or record microlecture video for students to watch anytime according to teaching goals, emphases and difficulties. [2] When the students are watching microlecture videos, the students can communicate with teachers at any time and teachers can answer questions of the students. Students can also discuss the questions each other, share the learning experience on the platform. The students ' learning enthusiasm is greatly improved thereby.

(c) Students will encounter problems in the daily use of the computer, such as computer black screen, computer cannot start normally, folders in flash drive cannot be opened, etc. Teachers can transform these problems into specific situation with problem-based learning method (PBL). Teachers allow the students together to solve complex, practical or authentic problems in the form of group cooperation. In this way, the scientific knowledge behind the questions is to promote the development of students' problem solving skills and cooperative ability and autonomous learning ability. Finally the completion of the task of the whole group is evaluated through the mutual assessment of groups and teacher evaluation. In this way, teachers can encourage students to participate in teaching activities and think actively and comprehensively use what they have learned 
to solve the problem. Finally the students can realize the sublimation of their ability to learn practical skills from theoretical knowledge.

(3) In view of the drawback that teaching practice aspect is relatively weak and experiment teaching effect is poor, teachers can adopt the method of virtual experiment.

(a) In the process of computer disassembly and assembly practice, teachers can use virtual reality software such as virtools to make virtual disassembly software to simulate the real experiment environment by using the mainstream computer hardware in the market. At the same time, teachers can publish the software to the course website platform based on campus network for students to download and exercise at any time. Through the application of virtual experiment environment, not only teachers can avoid the damage of the hardware in the course of students' practice, but also reduce the economic pressure of the school to a certain extent. For example, damage rate of CPU, hard disk, and memory is high and the price of these accessories is relatively expensive.

(b) In the process of BIOS setup, partition and format of hard disk, installation and backup of operating system, computer daily use and maintenance, and setup and application of computer networks, teachers can use virtual machine software (VMware) to build virtual machine operating system. [4-6] In the virtual machine operating system environment, students carry out the above experiments. Operating on the virtual platform teachers not only can avoid students' damage to the computer hard disk and computer system caused by improper control of theory or improper operation but also reduce the actual preparation time of the experiment. Taking into account the current high rate of student computer penetration teachers may recommend students to install VMware software on their own computers to build virtual machine operating system and encourage students to diligently practicing in their spare time, improve the ability to practice hands-on. The students can consolidate the practical effect and improve the practical ability in this way.

\section{Conclusions}

In summary we reform the teaching methods, integrate the teaching content in the process of teaching course of "Hospital Information Equipment Assembly and System Maintenance".We have reformed the traditional cramming method and introduced the mode of modularization, problem-based learning method and micro-class teaching mode in the aspect of design for teaching content. We have introduced virtual experiment mode in teaching practice aspect. The practice has proved that we have achieved good teaching results, stimulated students' interest of analysis and thinking and hands-on practice in deeply. We have improved the spirit of unity and cooperation among students which has great practical significance for improving students' practical ability.

\section{References}

[1] Du Lin, Teaching program research and practice of "Computer Assembly and Maintenance", J. Journal of Shandong Education Institute. 2008.3 96-98

[2] Hu Tiesheng, Understanding and teaching design methods of microlecture, J. Guangdong Education Comprehensive Edition. 2014 (4).

[3] Shen Gaofeng, Exploration of teaching methods for "Computer assembly debugging and maintenance technology", J. Computer Knowledge and Technology. 2010.15

[4] Xie Ruijie, Research of application for virtual machine technology in the "Computer Assembly and Maintenance" in higher vocational education, J .Computer Knowledge and Technology, 2013.15 3572-3574.

[5] Liang Dunhao, Application of virtual machine technology in the "computer assembly and maintenance of" teaching, J. Computer Knowledge and Technology. 2013 (09).

[6] Zhang ju. Application of virtual technology in computer specialty project training - A case of "Computer Assembly and Maintenance" course, J. Journal of Kaifeng Institute of Education 2013 